\title{
Role of LNG-IUS in adenomyosis in reproductive age group women: a prospective interventional study
}

\author{
Eshna Gupta ${ }^{1 *}$, Shashi Prateek², Poonam Mani², Lalita Yadav², Mamta Tyagi², Arushi Singh²
}

\begin{abstract}
${ }^{1}$ Department of Obstetrics and Gynecology, Dr. Baba Saheb Ambedkar Medical College and Hospital, Delhi, India ${ }^{2}$ Department of Obstetrics and Gynecology, Netaji Subhash Chandra Bose Subharti Medical College, Meerut, Uttar Pradesh, India
\end{abstract}

Received: 02 February 2019

Accepted: 08 February 2019

\author{
*Correspondence: \\ Dr. Eshna Gupta, \\ E-mail: guptaeshna@gmail.com
}

Copyright: ( $\odot$ the author(s), publisher and licensee Medip Academy. This is an open-access article distributed under the terms of the Creative Commons Attribution Non-Commercial License, which permits unrestricted non-commercial use, distribution, and reproduction in any medium, provided the original work is properly cited.

\section{ABSTRACT}

Background: The objective of the present study was to observe the efficacy of LNG-IUS in the treatment of heavy menstrual bleeding and dysmenorrhoea associated with adenomyosis.

Methods: LNG-IUS was inserted in forty women between 20-50 years of age presenting with heavy menstrual bleeding and dysmenorrhoea associated with adenomyosis diagnosed on transvaginal ultrasonography and followed up after 1 month, 3 months and 6 months of insertion. Subjective assessment of menstrual blood loss was done by pictorial blood loss assessment chart and dysmenorrhoea was assessed on the basis of universal pain assessment tool and side effects were noted at each visit.

Results: Mean patients' age was between 31-40 years (72.5\%) and the follow up duration was 6 months. Significant improvements in dysmenorrhea, HMB and haemoglobin levels were observed. There was no significant change in the uterine volume. The most common side effect was prolonged vaginal spotting $(n=26,65 \%)$ and pain abdomen $(n=13$, $32.5 \%)$. LNG-IUS expulsion was observed in 1 patient $(n=1,2.5 \%) .3$ patients underwent hysterectomy $(n=3,7.5 \%)$. The overall success rate of LNG-IUS was $82.5 \%$.

Conclusions: The LNG-IUS appears to be an effective method in alleviating dysmenorrhoea and heavy menstrual bleeding associated with adenomyosis during 6 months of study. It may be a valuable long-term alternative for the treatment of adenomyosis in young and perimenopausal women and it is a good strategy to reduce the number of hysterectomies in women with adenomyosis.

Keywords: Adenomyosis, Dysmenorrhea, Levonorgestrel-releasing intrauterine system

\section{INTRODUCTION}

Adenomyosis of the uterus is a common condition among women in 30-50 years of age group and is thought to affect $1 \%$ of women. ${ }^{1}$ The first description of the condition initially referred to as "adenomyoma" was provided in 1860 by the German pathologist Carl von Rokitansky, who found endometrial glands in the myometrium and subsequently referred to this finding as "cystosarcoma adenoids uterinum". The modern definition of adenomyosis was provided in 1972 by Bird who stated: "Adenomyosis may be defined as the benign invasion of endometrium into the myometrium, producing a diffusely enlarged uterus which microscopically exhibits ectopic non-neoplastic, endometrial glands and stroma surrounded by the hypertrophic and hyperplastic myometrium". ${ }^{2}$

Adenomyosis is defined thus, by the presence of ectopic endometrial glands and stroma within the myometrium, and hypertrophy and hyperplasia of surrounding adjacent myometrium. ${ }^{3}$ The etiology is unclear and the most 
frequent presenting symptoms are painful as well as heavy menstrual bleeding (HMB) periods, although many women are asymptomatic. The clinical presentation of adenomyosis is usually a multiparous, perimenopausal patient complaining of dysmenorrhoea and menorrhagia, though the diagnosis is difficult to obtain without histological confirmation. However, recent advances in diagnostic methods and new investigations of treatment methods have changed the management of adenomyosis. It can be diagnosed by transvaginal ultrasonography (TVUSG) with the use of some specific criteria, like globular-appearing uterus, heterogeneous myometrial echo texture, sub-endometrial myometrial cysts, asymmetric thickness of the anteroposterior wall of the myometrium, sub-endometrial echogenic linear striations or poor definition of the endometrial-myometrial junction. ${ }^{1}$

HMB is the most common cause of iron-deficiency anaemia at a premenopausal age. It is estimated to occur in $30 \%$ of women in their reproductive years. The definition and diagnosis of $\mathrm{HMB}$ is made when the duration of bleeding is equal to or greater than six days or blood-loss is at least $80 \mathrm{ml}$. However, many women seek consultation for even milder bleeding episodes due to the associated stress, discomfort, and quality of life impairment, thus making HMB one of the most frequent reasons for gynaecological consultation.

Hysterectomy is generally used to treat women with this condition but there are less invasive options than hysterectomy for the treatment of heavy menstrual bleeding, such as endometrial resection and the levonorgestrel-releasing intrauterine system (LNG IUS), which has become popular. ${ }^{1}$

Along with the high contraceptive efficacy, LNG-IUS has shown benefits and improvement of symptoms in menorrhagia, adenomyosis and endometriosis. LNG-IUS device has also been found to be cost-effective with less side effects and to increase the quality of life (QOL). The QOL of women treated with the LNG-IUS is markedly improved, causing high levels of patient satisfaction. ${ }^{4}$

Levonorgestrel is a potent progestin of 19nortestosterone. LNG-IUS consists of a T-shaped polyethylene frame (T-body) with a steroid reservoir (hormone elastomer core) around the vertical stem. The reservoir consists of an almost white cylinder made of a mixture of levonorgestrel and silicone (polydimethylsiloxane), containing a total of $52 \mathrm{mg}$ levonorgestrel. The reservoir is covered by a semi-opaque silicone membrane. The T-body is $32 \mathrm{~mm}$ in both the horizontal and vertical directions. The polyethylene of the T-body is compounded with barium attached to a loop at the end of the vertical stem of the T-body. The LNG-IUS releases a therapeutic daily dose of levonorgestrel $(20 \mu \mathrm{g} /$ day $)$ for 5 years. The capillary network of the basal endometrial mucosa quickly absorbs intrauterine LNG and measurable levels of LNG have been detected in plasma $15 \mathrm{~min}$ after insertion. The peak plasma LNG concentrations of sub-dermal implants are $400 \mathrm{pg} / \mathrm{mL}$, while those with LNG-IUS would correspond to about half the values of implants. Peak plasma LNG concentrations can be detected within a few hours after insertion, which level off at $150-200 \mathrm{pg} / \mathrm{mL}$ (0.4$0.6 \mathrm{nmol} / \mathrm{L})$. Levonorgestrel is continuously released from LNG-IUS, which means that there are no "peaks and troughs' in serum LNG levels unlike that of oral progesterone dosing. ${ }^{5}$

LNG down regulates the estrogen and progesterone receptors. The expression of some of the cytokines and the growth factors has been found to show variable responses. The cyclical activity of endometrium is lost after the insertion of LNG-IUS and the endometrium becomes dormant and nonresponsive to estrogen. This change in the endometrium is associated with irregular bleeding or spotting during the initial months of LNGIUS use. ${ }^{5}$

The LNG-IUS targets the endometrium directly by releasing of LNG. This results in the high local LNG concentrations that cause uniform suppression of endometrial proliferation, inactive histology, thin epithelium, and decidualization of the stroma. LNG-IUS decreases the menstrual blood loss and pain by the suppression of endometrial proliferation. ${ }^{5}$

The LNG-IUS, by its virtue of causing scanty bleeding or amenorrhoea would be suitable for Indian women as long acting contraceptive as well as a long-term treatment option for HMB and treating anaemia.

To help fill the gap in the existing knowledge, this study was designed to investigate the role of LNG-IUS in management of heavy menstrual bleeding and dysmenorrhoea in the patients of adenomyosis. It is relatively new area of research for the betterment of patient care.

\section{METHODS}

This study was a prospective interventional study conducted in the department of Obstetrics and Gynecology, Chattrapati Shivaji Subharti Medical College and Hospital, Meerut, Uttar Pradesh, over a period of two years from 2015 to 2017 .

\section{Inclusion criteria}

- Women between 30-50 years complaining of heavy menstrual bleeding and/or dysmenorrhoea in adenomyosis.

\section{Exclusion criteria}

- Pregnant and lactating patients, patients with congenital or acquired uterine anomaly, uterine fibroid, acute pelvic inflammatory disease, genital 
bleeding of unknown etiology, known or suspected carcinoma of breast, uterus and cervix, hepatic disease, renal disease, neurological disease or endocrinological disease, severe cardio-respiratory disorders, morbid obesity, uncontrolled systemic hypertension.

Detailed history of the patient, general physical and systemic examination was done. Per abdominal examination was done for all subjects followed by per speculum and per vaginal examination. It was done to assess the position, size, shape, mobility, consistency and tenderness of uterus. Both adnexa were examined, and findings were noted.

Complete hematological and biochemical screening was done which included Hemoglobin, Total leucocyte count, Differential leucocyte count, ESR, Blood sugar, Lipid profile, Urine-routine and microscopy, TSH, ECG and Chest X-ray to look for inclusion and exclusion criteria. Opportunistic pap smears were taken. Transvaginal ultrasonography was done to diagnose adenomyosis and exclude other possible causes of heavy menstrual bleeding including myomas and endometrial polyps, as well as adnexal pathology before insertion of LNG-IUS. It was done for all patients in the outpatient department of Obstetrics and Gynaecology only using USG Samsung SOMOACE-X8 machine. Endometrial histopathology were done to exclude any cervical or uterine pathology (except adenomyosis). After approval from the ethical committee the patients who fulfilled the inclusion criteria were enrolled for this study and a written and informed consent was taken. After approval from the ethical committee of our hospital, LNG-IUS.

Subjective assessment of menstrual blood loss was done with pictorial blood loss assessment chart (PBAC). A score was calculated by multiplying number of pads used with duration of flow with degree of staining 1, 5, 20 for slightly, moderately, and heavily soiled pad respectively. PBAC score $\geq 100$ was considered as HMB which means menstrual blood loss $\geq 80 \mathrm{ml}$. Dysmenorrhoea was assessed on the basis of universal pain assessment tool. Haemoglobin level of all patients was examined prior to the study and during follow up visits to assess any change in grading of anaemia using photometry method by Horiba medical (Pentra XLR and ABX Pentra 80) machine in department of Pathology of our hospital. Counselling was done regarding the altered menstrual pattern before and after LNG-IUS insertion and in all follow up visits. Post insertion, the patients were asked to maintain and show a menstrual calendar in the follow up visits at 1 st month, 3rd month, and 6th month. Changes in menstrual pattern and associated complications were noted in the subsequent visits. A detailed general, systemic, pelvic and breast examination, along with hemoglobin level and pelvic ultrasound was done at every visit. LNG-IUS was measured in the form of subjective and symptomatic improvement in the quality of life.

\section{RESULTS}

Forty women diagnosed with adenomyosis were enrolled in the study with mean age of $36.40 \pm 5.19$ years. While 4 $(10.0 \%)$ patients were of 30 years of age, $30(75.0 \%)$ were in the age group of 31 to 40 years and remaining 6 $(15.0 \%)$ patients were in the age group of 41 to 48 years of age. Most of the patients $(40 \%)$ were para 2 followed by $14(35 \%)$ patients who were para 3 .

The given table (Table1) shows the distribution of Clinical Symptoms of the studied patients. While 39 $(97.5 \%)$ patients had heavy menstrual bleeding at the time of presentation, $14(35.0 \%)$ had dyspareunia, all of them had pain or discomfort associated with menstruation called dysmenorrhoea and remaining 10 (25.0\%) patients had Irregular menstrual bleeding problem.

Table 1: Distribution of clinical symptoms of the studied patients.

\begin{tabular}{|l|l|l|}
\hline \multirow{2}{*}{ Clinical symptoms } & \multicolumn{2}{|c|}{ No. of patients $(\mathbf{N}=40)$} \\
\hline HMB & Number & \% \\
\hline Dyspareunia & 39 & 97.5 \\
\hline Dysmenorrhoea & 14 & 35.0 \\
\hline Irregular menstrual bleeding & 40 & 100.0 \\
\hline
\end{tabular}

Table 2 represents the clinical signs of the studied patients on the day of registration (before treatment). While $6(15.0 \%)$ patients had Uterine size of 12 weeks, $11(27.5 \%)$ patients had 10 weeks Uterine size, 10 (25.0\%) had 8 weeks Uterine size and 13 (32.5\%) patients had uterine size of 6 weeks.

Table 2: Clinical signs of studied patients on the day of registration (before treatment).

\begin{tabular}{|l|l|l|l|}
\hline \multirow{2}{*}{ Clinical signs } & \multicolumn{3}{c|}{ No. of patients $(\mathbf{N}=40)$} \\
\hline \multirow{3}{*}{ Uterine size } & 12 weeks & 17 & 42.5 \\
\hline & 10 weeks & 10 & 25 \\
\cline { 2 - 4 } & 8 weeks & 13 & 32.5 \\
\hline Uterine tenderness & 40 & 100 \\
\hline
\end{tabular}

As far as uterine tenderness was concerned, all the 40 $(100 \%)$ patients had uterine tenderness. During the course of their $1^{\text {st }}$ visit, the uterine size of 6 patients was of 12 weeks, for 11 patients was of 10 weeks, for 10 patients the uterine size was 8 weeks and for 13 others uterine size was of 6 weeks only.

During the course of their $2^{\text {nd }}$ visit the uterine size, of 4 patients was of 12 weeks, for 12 patients it was 10 weeks, for 11 patients the uterine size was 8 weeks and for 13 others, uterine size was of 6 weeks only.

During the course of their $3^{\text {rd }}$ visit the uterine size of 2 patients was 12 weeks, for 13 patients' uterine size was 
10 weeks, for 10 patients the uterine size was 8 weeks and for 14 others uterine size was of 6 weeks only. As far as Uterine tenderness was concerned during 1 st visit uterine tenderness was noticed in as many as 39 cases. During $2^{\text {nd }}$ and $3^{\text {rd }}$ visits however, the uterine tenderness noticed was in 23 cases during 2nd visit and 6 cases only during 3 rd visit. While difference observed in the uterine size from the day of insertion till 6 months follow up visits was not statistically significant $(\mathrm{P}>0.05)^{*}$, the decrease in uterine tenderness at the end of 6 months of treatment was statically significant $(\mathrm{P}<0.05)$. In follow up, the changes in initial symptoms were studied which are reported in the table below (Table 3). During their $1^{\text {st }}$ visit $5(12.5 \%)$ patients complained about Polymenorrhoea, $26(65.0 \%)$ patients complained of Intermenstrual spotting and no patient complained of oligomenorrhoea, hypomenorrhoea and amenorrhoea.
During the course of their $2^{\text {nd }}$ visit none of the patients mentioned about polymenorrhoea, hypomenorrhoea and amennorrhoea, $6 \quad(15.0 \%)$ complained of oligomenorrhoea, and $24(60.0 \%)$ about intermenstrual spotting. During the course of their $3^{\text {rd }}$ visit none of them complained of polymenorrhoea, 22 (55.0\%) had oligomenorrhoea, none with hypomenorrhoea, and amennorrhoea and $19(47.5 \%)$ patients complained of intermenstrual spotting. Table 4 , at insertion the mean PBAC score was 371.3 \pm 195.8. During first follow up visit the mean blood loss assessment figure was $333.2 \pm 206 \mathrm{ml}$, during the second visit it was $186.9 \pm 165$ $\mathrm{ml}$ and during the third visit the mean blood loss figure was $100.2 \pm 84 \mathrm{ml}$. The differences in the mean blood loss assessment figures of patients between 1 st and 2 nd, 2 nd and 3rd, 1st and 3rd and from insertion till 6 months of treatment were statistically significant $(\mathrm{P}<0.001)$.

Table 3: Changes in symptoms in subsequent visits.

\begin{tabular}{|c|c|c|c|c|}
\hline Symptoms & $\begin{array}{l}\text { First visit no. of } \\
\text { patients }(\mathrm{N}=40)\end{array}$ & $\begin{array}{l}\text { Second visit no. of } \\
\text { patients }(\mathrm{N}=40)\end{array}$ & $\begin{array}{l}\text { Third visit no. of } \\
\text { patients }(\mathrm{N}=39)\end{array}$ & P value \\
\hline Polymenorrhoea & $5(12.5 \%)$ & 0 & 0 & $>0.05^{*}$ \\
\hline Oligomenorrhoea & 0 & $6(15.0 \%)$ & $22(55.0 \%)$ & $<0.05^{\#}$ \\
\hline Hypomenorrhoea & 0 & 0 & 0 & $>0.05 *$ \\
\hline Amennorrhoea & 0 & 0 & 0 & $>0.05 *$ \\
\hline Intermenstrual spotting & $26(65.0 \%)$ & $21(52.5 \%)$ & $13(33.3 \%)$ & $>0.05 *$ \\
\hline
\end{tabular}

* P value was insignificant between first day and each visit; \# P value was significant statistically from first day;

* P value was insignificant between first, second and third visit; \# P value was statistically significant from $1^{\text {st }}$ visit to $2^{\text {nd }}$ and $3^{\text {rd }}$ visit.

Table 4: Changes in HMB patterns, pain scores and haemoglobin levels after treatment.

\begin{tabular}{|l|l|l|l|l|l|}
\hline Variable & At insertion $(\mathbf{N}=40)$ & At $^{\text {st }}$ month $(\mathbf{N}=40)$ & At $3^{\text {rd }}$ month $(\mathbf{N}=40)$ & At $^{\text {th }}$ month $(\mathbf{N}=39)$ & P value \\
\hline PBAC score & $371.3 \pm 195.8$ & $333.2 \pm 206$ & $186.9 \pm 165$ & $100.2 \pm 84$ & $<0.001$ \\
\hline Pain score & $8.4 \pm 1.2$ & $7.9 \pm 1.2$ & $5.8 \pm 1.5$ & $3.4 \pm 1.8$ & $\leq 0.001$ \\
\hline Hb levels $(\mathrm{g} / \mathrm{dl})$ & 7.8 & 8.4 & 9.1 & 9.6 & $<0.001$ \\
\hline
\end{tabular}

The mean Universal Pain Assessment Score of patients at insertion was $8.4 \pm 1.2$, during the 1 st visit was $7.9 \pm 1.2$, during 2 nd visit the mean score was $5.8 \pm 1.5$ and during the 3 rd visit the score was 3.4 \pm 1.8 . The differences in Universal Pain Assessment Scores of patients between 1 st and 2nd, 2nd and 3rd visit, 1st and 3rd visit and at insertion and at the end of 6 months were statistically highly significant $\mathrm{P} \leq 0.001$.

Mean haemoglobin levels increased from $7.8 \mathrm{~g} / \mathrm{dl}$ to $8.4 \mathrm{~g} / \mathrm{dl}$ after 1 month, $9.1 \mathrm{~g} / \mathrm{dl}$ after 3 months of insertion and $9.6 \mathrm{~g} / \mathrm{dl}$ after 6 months of insertion $(\mathrm{P}$ value $<0.001)$.

\section{DISCUSSION}

In the present study, $30(75 \%)$ patients diagnosed with adenomyosis belonged to 31-40 years age group and the mean age was $36.40 \pm 5.19$ years. The results of this study are in accordance with the study of Singh $\mathrm{K}$ et al who enrolled 42 women with abnormal uterine bleeding with mean age of $38.2 \pm 6.85$ years. ${ }^{4}$ Majority $(76.2 \%)$ of the patients belonged to 30-50 years of age group. Similarly, in a multicentric, retrospective, and observational study done by Mansukhani $\mathrm{N}$ et al, majority of the patients belonged to the age group of 35-40 years followed by 41 45 years of age group with mean age of 42.3 years. $^{6}$

However the results were in contrast to the study of Park DS et al who evaluated the clinical aspects of LNG-IUS in patients with large adenomyosis associated with dysmenorrhoea and/or heavy menstrual bleeding (HMB), observed that the mean age was $41.7 \pm 6.1$ years in a retrospective study of 48 patients with large adenomyosis. $^{7}$ Ahmet Uysal et all also reported $43.2 \pm$ 0.8 years mean age of the 42 women in their study which was slightly higher than the mean age from the present study, because of inclusion criteria and geographical difference. 
Most of the patients (40\%) in this study were para 2 followed by $35 \%$ patients who were para 3 . The result coincided with the study of Park DS et al and AhmetUysal et al where the median of parity was 2 with range $0-3$ and mean parity was $3.01 \pm 1.4$ with range $0-5$ respectively. ${ }^{1,7}$

Approximately 39 out of $40(97.5 \%)$ patients in this study had both heavy menstrual bleeding and dysmenorrhoea at the time of registration and all the patients had dysmenorrhoea (Table 1). The results were similar to the study conducted by Ahmet Uysalet al in which all the patients with adenomyosis complained of HMB. In the study of Park DS et al, 62.5\% patients reported with HMB and dysmenorrhoea. ${ }^{1,7}$ In the prospective interventional study done by Singh $\mathrm{K}$ et al, it was observed that $69 \%$ patients had dysfunctional uterine bleeding, $14.3 \%$ had fibroid uterus, $9.5 \%$ patients had adenomyosis and rest patients had menorrhagia associated with endometriosis and severe dysmenorrhoea. ${ }^{4}$

In this study, at the end of 6 months, $55 \%$ patients had oligomenorrhoea and none with polymenorrhoea, hypomenorrhoea and amenorrhoea (Table 3). In a study by Garg et al at six months post LNG- IUS insertion $10 \%$ had amenorrhea, $40 \%$ had irregular spotting (decreased flow), $23.33 \%$ had infrequent bleeding, 20\% had scanty regular bleeding and only two women (6.66\%) had irregular heavy bleeding. ${ }^{8}$ By the end of 12 months, $90 \%$ of women in this group developed amenorrhea. In other recent study by Singh $\mathrm{K}$ et al, at 6 months $13.9 \%$ had amenorrhea, $44.44 \%$ had scanty menstrual flow $11.1 \%$ had irregular spotting, $16.7 \%$ had normal menstrual cycle, and only 5 (13.89\%) patients had Irregular heavy bleeding. ${ }^{4}$ At 1 year of use $81.5 \%$ had amenorrhea, $11.1 \%$ had regular scanty flow and only $2(7.4 \%)$ had irregular spotting.

Post LNG-IUS insertion, symptomatic relief in menstrual pattern was evaluated (by PBAC scores) and it was seen that at first month follow up visit, all 39 (100\%) patients who initially had HMB continued to have HMB. By the end of 3rd month $75 \%$ still complained of HMB but by the end of 6th month, 35\% patients had significant improvement in menstrual bleeding patterns was noted. In one patient, there was spontaneous expulsion of LNGIUS at the end of third month, 3 patients opted for removal of LNG-IUS at the end of 6th month and opted for hysterectomy because of persistence of clinical symptoms. In all others there was a significant difference seen in changes in menstrual blood flow in the follow up visits $(\mathrm{P}$ value $<0.001)$ (Table 4$)$. Similar results were observed in the study conducted by Ahmet Uysal et al and Park DS et al. ${ }^{1,7}$ Universal Pain Assessment score was used to analyze dysmenorrhoea at insertion and at follow up visits in present study. The differences in Universal Pain Assessment Scores of patients between 1 st and 2nd, 2nd and 3rd visit, 1st and 3rd visit and at insertion and at the end of 6 months were statistically highly significant $\mathrm{P} \leq 0.001$ (Table 4). The study of Ahmet Uysal et al also reported statistically significant decrease in the thickness of the endometrium when the pre-treatment period was compared to $6^{\text {th }}$ and $12^{\text {th }}$ months $(\mathrm{P}<0.001) .{ }^{1}$ D.S. Park et al stated a decrease in the mean VAS score for dysmenorrhoea and HMB after LNG-IUS insertion. The mean symptom score for dysmenorrhoea remarkably decreased from $5.81 \pm 2.96$ to $2.86 \pm 2.8$ after 3 months $(\mathrm{P}<0.01)$; after 36 months, the mean symptom score decreased to $1.4 \pm 1.65(\mathrm{P}<0.01) .{ }^{8}$ The mean score for the subjective symptoms of HMB also decreased continuously similar to dysmenorrhoea (from 6.94 \pm 2.61 to $3.25 \pm 3.02$ after 3 months, $\mathrm{P}<0.01$; and to $0.89 \pm 1.27$ after 36 months, $\mathrm{P}<0.01$ which was similar to present study. Pain scores and PBAC scores dropped significantly after insertion of the device.

The difference in the mean haemoglobin levels of the patients from insertion till the end of $6^{\text {th }}$ month was statistically highly significant with $\mathrm{P}$ value $\leq 0.001$ (Table 4). In the study by Ahmet Uysal et al comprising of 42 patients, the average haemoglobin level was $10.2 \pm 0.5 \mathrm{~g} / \mathrm{dl}$ before treatment and $12.0 \pm 0.8 \mathrm{~g} / \mathrm{dl}$ at the end of 12 months. This difference was statistically significant $(\mathrm{P}$ <0.001). ${ }^{1}$ The reason for this improvement may be due to decrease in the amount of bleeding caused by use of LNG-IUS which resulted in raised haemoglobin concentration. India being a country where anaemia in women predominates, use of LNG-IUS which results in spotting and eventually amenorrhoea proves to be beneficial.

The most common complication in this study was intermenstrual spotting $(\mathrm{n}=40)$ which mostly occurred during the first two visits $(65 \%$ in 1 st month and $60 \%$ in 3rd month) and improved in the 3rd visit with only $47.5 \%$ patients complaining of intermenstrual spotting. The results of the study were in accordance with the study of Park DS et al where prolonged intermenstrual vaginal spotting $(n=28)$ was a common complication, which mostly occurred during the first 3 months $(n=18 ; 64.3 \%)$ and improved as time passed. Similar study was done by Taru $\mathrm{G}$ et al wherein prolonged intermenstrual spotting was observed at 3rd month of insertion (30\%) and at 6th month, $12.9 \%$ patients still complained of intermenstrual spotting. 7,9

In the present study, one patient reported expulsion of LNG-IUS. On examination, there was no finding suggestive of LNG-IUS lying in the cervical canal or in the vagina in any case or missing strings.

Three patients $(7.5 \%)$ requested removal of LNG-IUS and opted for hysterectomy after six months of treatment. This result coincides with the study conducted by Kalpana Singh et al in 2016 wherein $2(5.55 \%)$ patients opted for hysterectomy. ${ }^{4}$

In the study, $17.5 \%, 80 \%$ and $90 \%$ patients were satisfied with LNG-IUS after 1 month, 3 months and 6 months of 
insertion respectively. The result coincides with that of Singh $\mathrm{K}$ et al where $57.5 \%, 92.5 \%$ and $100 \%$ patients were satisfied with the device after 3 months, 1 year and 2 years of treatment respectively. ${ }^{4}$ The variation in result is only due to the different follow up time period. In the study by Yazbeck et al, $86.1 \%$ women with dysfunctional uterine bleeding were satisfied with the treatment with LNG-IUS as an alternative to hysterectomy..$^{10}$ The overall satisfaction scores were significantly more in the LNGIUS group as compared to the hysterectomy group with $90 \%$ women being satisfied with the treatment in the LNG-IUS group and only $50 \%$ being satisfied in the hysterectomy group. ${ }^{10} \mathrm{~A}$ total of $70.3 \%$ patients with fibroids were satisfied and $82.4 \%$ said that they would recommend this treatment to other users as reported by Mansukhani $\mathrm{N}$ et al. ${ }^{6}$

\section{CONCLUSION}

Thus, to conclude, LNG-IUS is a safe, effective, reversible and acceptable mode of treatment for heavy menstrual bleeding and dysmenorrhoea in the patients of adenomyosis and can be a good alternative to hysterectomy. It is associated with lesser side effects and higher satisfaction rate. LNG-IUS can be choice of treatment for entire reproductive years and it also helps in smooth transition to menopause. So, hysterectomy should be avoided to give a choice of reversible alternative to the patient at her own will and side by side preserving her fertility status.

Funding: No funding sources Conflict of interest: None declared

Ethical approval: The study was approved by the Institutional Ethics Committee

\section{REFERENCES}

1. Uysal A, Taner CE, Mun S, Uysal F, Celimli FH. Use of levonorgestrel: releasing intrauterine device in the treatment of adenomyosis associated with heavy menstrual bleeding. J Pak Med Assoc. 2013; 63(11):1349-52.

2. Benagiano G, Brosens I. History of adenomyosis. Best Pract Res Clin Obstet Gynaecol. 2006;20(4):449-63.
3. Kepkep K, Tuncay YA, Göynümer G, Tutal E. Transvaginal sonography in the diagnosis of adenomyosis: which findings are most accurate? Ultrasound Obstet Gynecol. 2007;30(3):341-5.

4. Singh K, Bharati G, Prasad D, Kumari S. Role of levonorgestrel releasing intrauterine device in management of heavy menstrual bleeding: a conservative approach. Int J Reprod Contracept Obstet Gynecol. 2017;6(2):631-5.

5. Magon N, Chauhan M, Goel P, Malik S, Kapur K, Kriplani A, Dhaliwal L, Pandit SN. Levonorgestrel intrauterine system: Current role in management of heavy menstrual bleeding. J Mid-life Health. 2013;4(1):8.

6. Mansukhani N, Unni J, Dua M, Darbari R, Malik S, Verma S, et al Are women satisfied when using levonorgestrel releasing intrauterine system for treatment of abnormal uterine bleeding? J Midlife Health. 2013;4(1):31-5.

7. Park SD, Kim M, Song T, Yun BS, Kim MK, Jun HS, et al. Clinical experiences of the levonorgestrelreleasing intrauterine system in patients with large symptomatic adenomyosis. Taiwan $\mathbf{J}$ Obstet Gynecol. 2015;54(4):412-5.

8. Garg S, Soni A. A Non-surgical lifeline for Abnormal uterine bleeding (AUB) - the LNG IUS. Ind J Obstet Gynecol Res. 2016;3(1):23-7.

9. Taru G, Nupur G, Sangeeta G, Pushpa B, Jyoti J, Sushma K. Levonorgestrel intrauterine system (LNG IUS) in menorrahgia: a follow-up study. Open $\mathbf{J}$ Obstet Gynecol. 2014;4(04):190.

10. Yazbeck C, Omnes S, Lavenu VMC, Madelenat P. Levonorgestrel-releasing intrauterine system in the treatment of dysfunctional uterine bleeding: A French multicenter study. Gynecol Obstet Fertil. 2006;34(10):906-13.

Cite this article as: Gupta E, Prateek S, Mani P, Yadav L, Tyagi M, Singh A. Role of LNG-IUS in adenomyosis in reproductive age group women: a prospective interventional study. Int J Reprod Contracept Obstet Gynecol 2019;8:1254-9. 